\title{
Modernização do Ensino de Biologia Tecidual
}

\author{
Fábio Siviero* e Sérgio Ferreira de Oliveira \\ Departamento de Biologia Celular e do Desenvolvimento \\ Instituto de Ciências Biomédicas da Universidade de São Paulo
}

\section{GradP \\ Revista de Graduação USP}

\footnotetext{
* Autor para correspondência: fsiviero@usp.br
}

\section{RESUMO}

Relatamos no presente artigo a mudança de paradigma no ensino de Biologia Tecidual advinda da adoção de tecnologias digitais como ferramentas de visualização e interação com o conteúdo a ser ministrado. Tal processo de modernização ocorreu no âmbito do Departamento de Biologia Celular e do Desenvolvimento da USP, onde já foi utilizado em diversas disciplinas e remodelou o ensino oferecido a milhares de estudantes, tornando-o mais eficiente e posicionando o aluno como um agente ativo no processo de aprendizado.

Palavras-chave: Biologia Tecidual; Histologia; Microscópio Virtual; Laminário Virtual; Conteúdo On-line.

\begin{abstract}
We report in this paper the paradigm shift in Tissue Biology education arising from the adoption of digital technologies acting as content visualization and interaction tools. This modernization process took place in the Department of Cell and Developmental Biology, on which has been applied in various disciplines and restructured the education offered to thousands of students, making it more efficient and positioning the student as an active agent in the learning process.
\end{abstract}

Keywords: Tissue Biology; Histology; Virtual Microscope; Virtual Slides; On-line Content.

\section{Introdução}

O ensino de Biologia Tecidual é um exemplo interessante de atividade que envolve contrastes: reúne o clássico e o moderno. Como disciplina, evoluiu concomitantemente com a tecnologia dos microscópios desde o século XVII, e seu conteúdo foi refinado com o avanço da qualidade das imagens produzidas. Hoje se beneficia de sistemas robotizados que influenciam até mesmo a forma como se definem os diagnósticos. Seu conteúdo se mostra essencialmente descritivo, morfológico, o que pode repelir o interesse de parte dos estudantes. Ao mesmo tempo, o uso de equipamentos e metodologias diretamente relacionados à futura atuação profissional dos graduandos acaba atraindo a atenção deles. Disciplina essencial, a Biologia Tecidual, também chamada de Histologia, geralmente figura como parte de um ciclo básico de ensino para as áreas de biológicas e da saúde, fundamentando o entendimento de fisiologia, anatomia e patologia, entre outras áreas do conhecimento.

Biologia Tecidual apresenta vasto conteúdo, que deve ser transmitido aos estudantes em tempo cada vez mais restrito. As novas gerações, por sua vez, revelam-se cada vez mais tecnologicamente hábeis e acostumadas com o uso de recursos interativos. Desse modo, não se mostram muito estimuladas pelo ensino convencional e unidirecional (docente ativo - estudante ouvinte passivo), mesmo quando se utilizam recursos audiovisuais.

\section{Mudança de Paradigma}

Aqui relatamos as mudanças advindas da adoção de novas ferramentas no ensino de Biologia Tecidual no Departamento de Biologia Celular e do Desenvolvimento do Instituto de Ciências Biomédicas da USP. Nosso departamento apresenta um rico histórico na produção de conteúdo para 
o ensino, sejam livros e atlas, sejam materias on-line e cursos a distância. Muitos desses trabalhos se destacaram e se tornaram referências na área (JUNQUEIRA \& CARNEIRO, 2013). Também mostra tradição na adoção de tecnologias atuais, sendo que uma das últimas ferramentas empregadas em nossas salas de aula foi o Laminário Virtual, um sistema digital de ensino de Biologia Tecidual.

Em 2008, a chefia do departamento teve a iniciativa de introduzir o uso de imagens digitais no ensino de Biologia Tecidual. Naquele momento, não havia muitas opções comerciais disponíveis ou voltadas diretamente ao ensino, nem opções viáveis de código aberto. Diversas alternativas foram pesquisadas, mas a iniciativa sempre esbarrava em empecilhos técnicos ou em custos proibitivos.

Finalmente, adotamos uma solução baseada em um sistema de telepatologia, em que lâminas poderiam ser digitalizadas em microscópios robotizados em aumento real, e suas imagens tornavam-se passíveis de serem observadas em qualquer computador mediante a utilização de um visualizador simples e de conexão com a internet. Soluções semelhantes obtiveram ótimos resultados na modernização do ensino em outras instituições (KRIPPENDORF \& LOUGH, 2005; BLOODGOOD, 2012; CAMPBELL, 2013, p. 17; MIONE et al., 2013).

$\mathrm{Na}$ prática, as salas de aulas foram equipadas com uma infraestrutura de rede cabeada de $1 \mathrm{~Gb} / \mathrm{s}$ e computadores de baixo custo, que se conectam a um servidor contendo as imagens digitalizadas em um banco de dados relacional. Deu-se especial atenção aos monitores, telas de 22 polegadas com tecnologia LED e ângulos de visão de $170^{\circ}$, como meio de permitir uma confortável visualização dos conteúdos apresentados por grupos de até quatro estudantes.

A mudança no paradigma de aulas foi imediata. Antes, duplas de alunos utilizavam um microscópio e uma caixa de lâminas, demonstrações eram feitas em telas projetadas a partir de um microscópio equipado com uma câmera CCD de uso do docente, múltiplos pós-graduandos que atuavam como monitores se faziam necessários para acompanhar as aulas práticas e sanar dúvidas passeando pela sala, e, quando uma estrutura interessante era encontrada em uma lâmina de uma determinada dupla, filas se formavam para a observação dela. As aulas se tornavam longas, cansativas, e os alunos dispersavam sua atenção, devido à formação de diversos subgrupos em aula.

O uso do Laminário Virtual (Figura 1) permite que um único docente orquestre sua aula em turmas de grande porte, mesmo sem o apoio de monitores. Uma ferramenta chamada "Modo Conferência" sincroniza as imagens da tela do professor com as telas dos estudantes, exibindo em alta resolução para toda a turma as estruturas de interesse, com recursos de anotação, desenho sobre a imagem e medição. Os alunos podem ainda solicitar atenção em tela ao professor, que pode transferir o comando da apresentação ao aluno, para que ele mesmo aponte suas dúvidas. Tudo em tempo real e para toda a turma.

As aulas tornaram-se dinâmicas. Não se observam mais filas em sala, as dúvidas, que muitas vezes eram repetidas por diferentes grupos de alunos, agora são sanadas para toda a turma. Reduziu-se muito, assim, o tempo e o esforço exigidos para uma aula prática. A busca por imagens no banco de dados se faz rapidamente, a organização em sala se mostra natural, e a aula se torna fluida. De fato, a otimização de uso do acervo e dos recursos disponíveis é tão grande que alguns docentes bem-adaptados ao novo sistema passaram a ministrar aulas teórico-práticas, utilizando o Laminário Virtual como um recurso durante explanações teóricas.

Com o sistema de imagens digitais, o uso dos microscópios deluznão foiabolido. Os alunos aprendem a manusear corretamente este equipamento nas primeiras aulas, em especial naquelas referentes ao estudo dos tecidos básicos (Figura 2). Mas, à medida que as aulas exigem a observação de maior número de lâminas e estruturas mais complexas, o laminário digital substitui o microscópio como ferramenta, ou é utilizado concomitantemente. Assim, os alunos são capacitados no uso de equipamentos amplamente disseminados, como os microscópios de luz clássicos, bem como no emprego de novas tecnologias 


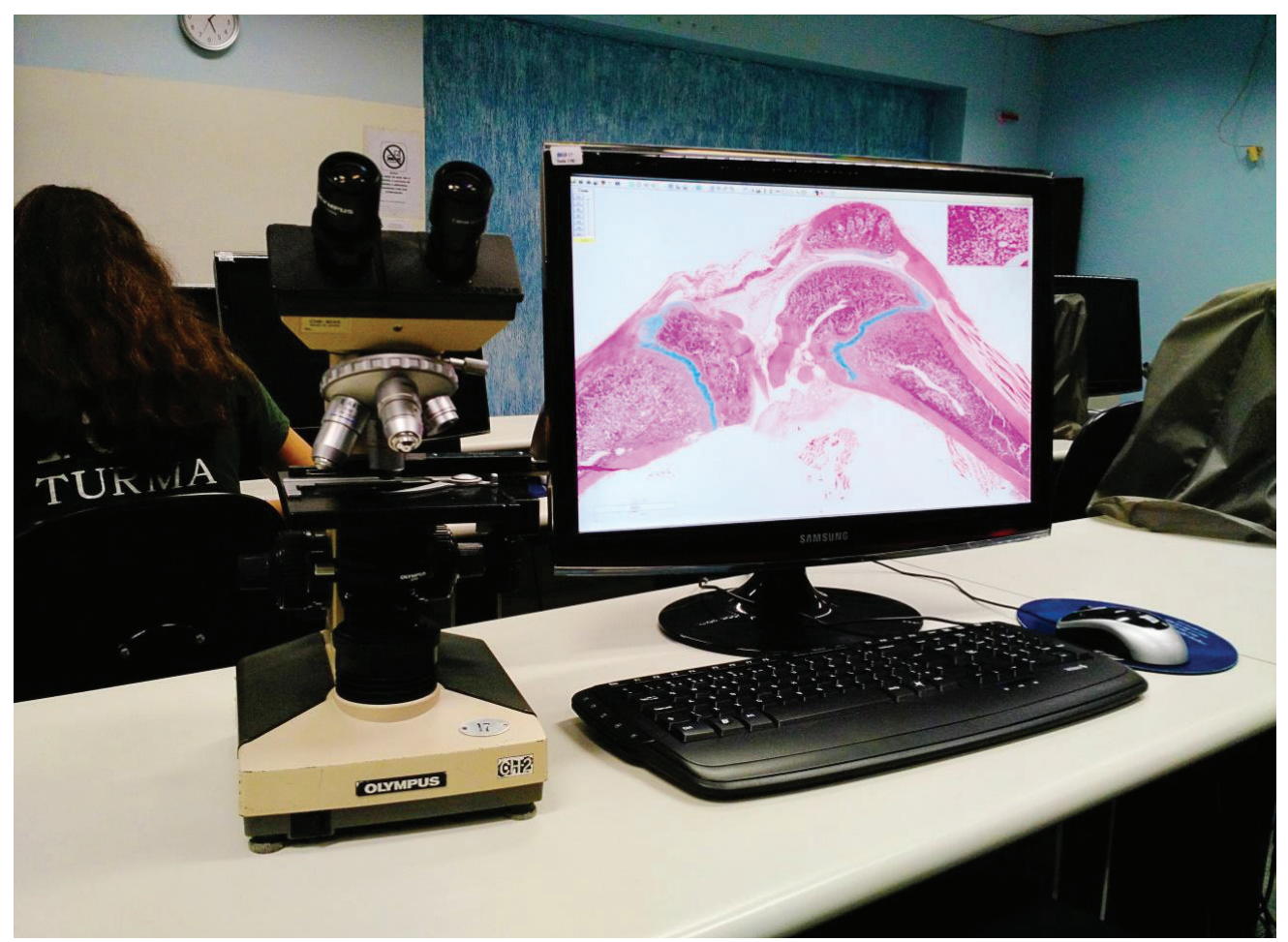

Figura 1 - Equipamentos disponíveis aos alunos nas salas de aula de Biologia Tecidual.

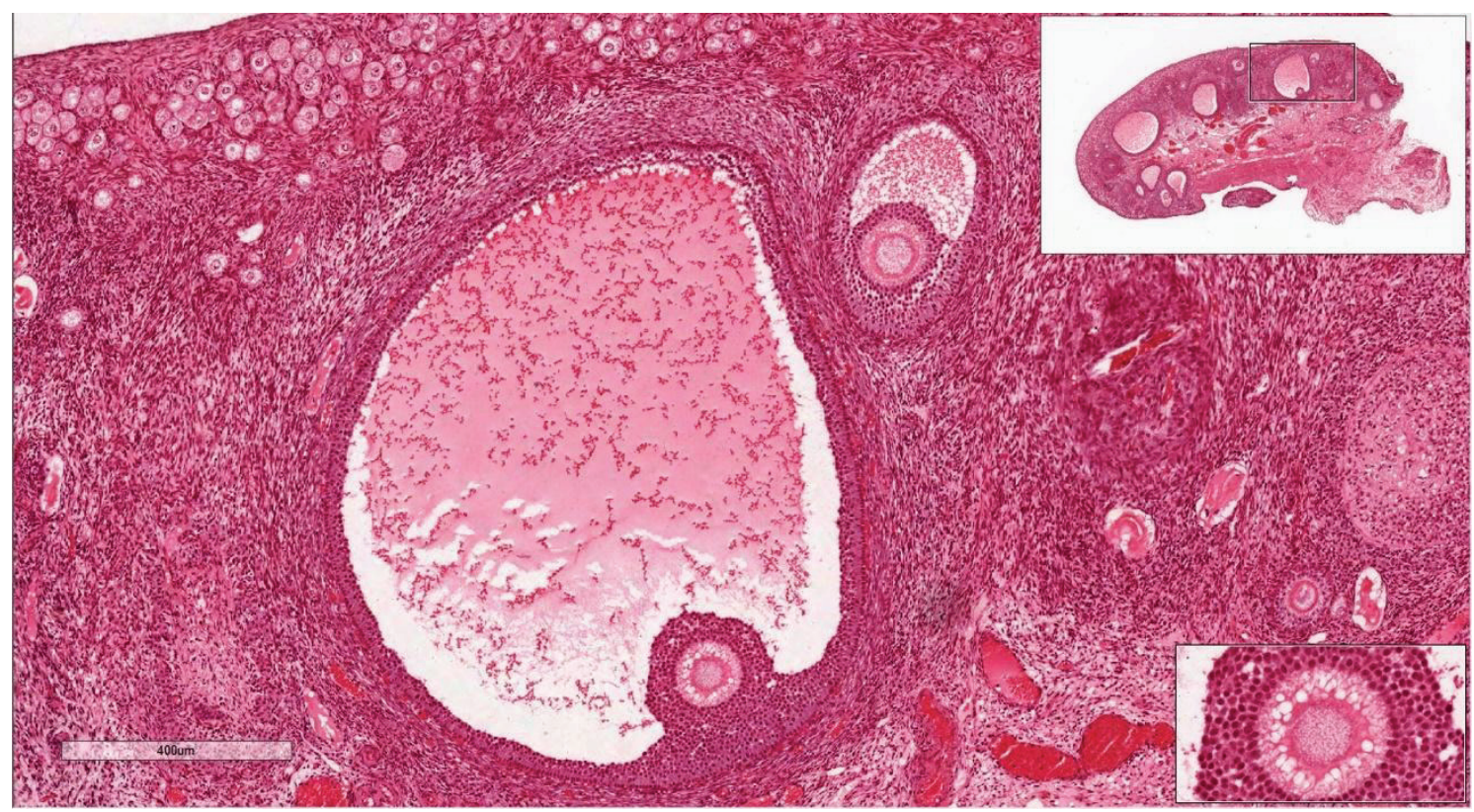

Figura 2 - Típica tela de visualização das lâminas. No canto superior direito há uma visão macroscópica da lâmina; no canto inferior direito, uma lupa digital com aumento de $2 \mathrm{X}$ cujo foco acompanha o cursor; no canto inferior esquerdo visualizamos uma escala referente à imagem de fundo que se ajusta dinamicamente. Esse conjunto de ferramentas facilita ao estudante localizar o campo de visualização, bem como os detalhes e as dimensões relativas de estruturas.

digitais presentes em modernos centros de diagnósticos e pesquisa.

Dentre as preocupações iniciais, duas se destacavam: 1) Como os alunos lidariam com o novo recurso; e 2) Como seria a aceitação dele pelos colegas docentes.

Em relação aos alunos, o Laminário Virtual foi incorporado, logo de imediato, como algo rotinei- 
ro na dinâmica das atividades realizadas em sala de aula (Figura 3). Por apresentar características lúdicas, os estudantes se interessam de imediato por tal ferramenta e passam a explorar o conteúdo e as possibilidades por ela oferecidos antes mesmo de disponibilizarmos roteiros ou estudos dirigidos. A possibilidade de exibir simultaneamente tecidos diferentes na tela, comparar medidas de estruturas, anotar a posição de pontos de interesse, entre outros recursos, acabam por aguçar a curiosidade dos estudantes, e eles dedicam tempo à observação de lâminas sem considerar isso uma tarefa obrigatória. Temores de que os equipamentos e os softwares representariam distrações durante as aulas foram rapidamente superados, não se configurando como ameaças maiores do que o conteúdo de suas próprias mochilas.

Entre os docentes, a nova ferramenta foi bem aceita. As aulas mais eficientes e menos exaustivas advogam em favor do seu uso. Mesmo os mais receosos e menos hábeis com novas tecnologias a utilizam de forma adequada. Na realidade, o emprego do Laminário Virtual passou a ser uma exigência dos estudantes; e mesmo que o docente não se sinta à vontade para utilizar seus recursos, os próprios alunos controlam o software sob a orientação do professor a partir de seus próprios terminais, sem pôr em risco os dados do servidor.

Atualmente, o Laminário Virtual conta com 556 lâminas, que visam a ilustrar histologia básica, histologia dos sistemas e biologia do desenvolvimento. Contamos com cortes de diferentes espécies que utilizam diversas colorações e oferecem seleções especiais de conteúdo adequado para o ensino voltado à medicina e ciências da saúde, veterinária, biologia, enfermagem e odontologia, entre outros. Nossas salas de aula, nos períodos em que não estão sendo utilizadas para aulas, são abertas para os alunos estudarem. Os discentes se valem dos recursos disponíveis em tais espaços, podendo formar grupos de estudo independentes e usar múltiplas conferências simultâneas.

Ao primeiro contato com o Laminário Virtual, os alunos, quase de imediato, solicitam que o conteúdo mobilizado em sala de aula possa ser acessado de casa, surgindo assim uma demanda muito forte por um conteúdo on-line. De fato, a disponibilização de imagens de histologia é uma ten-

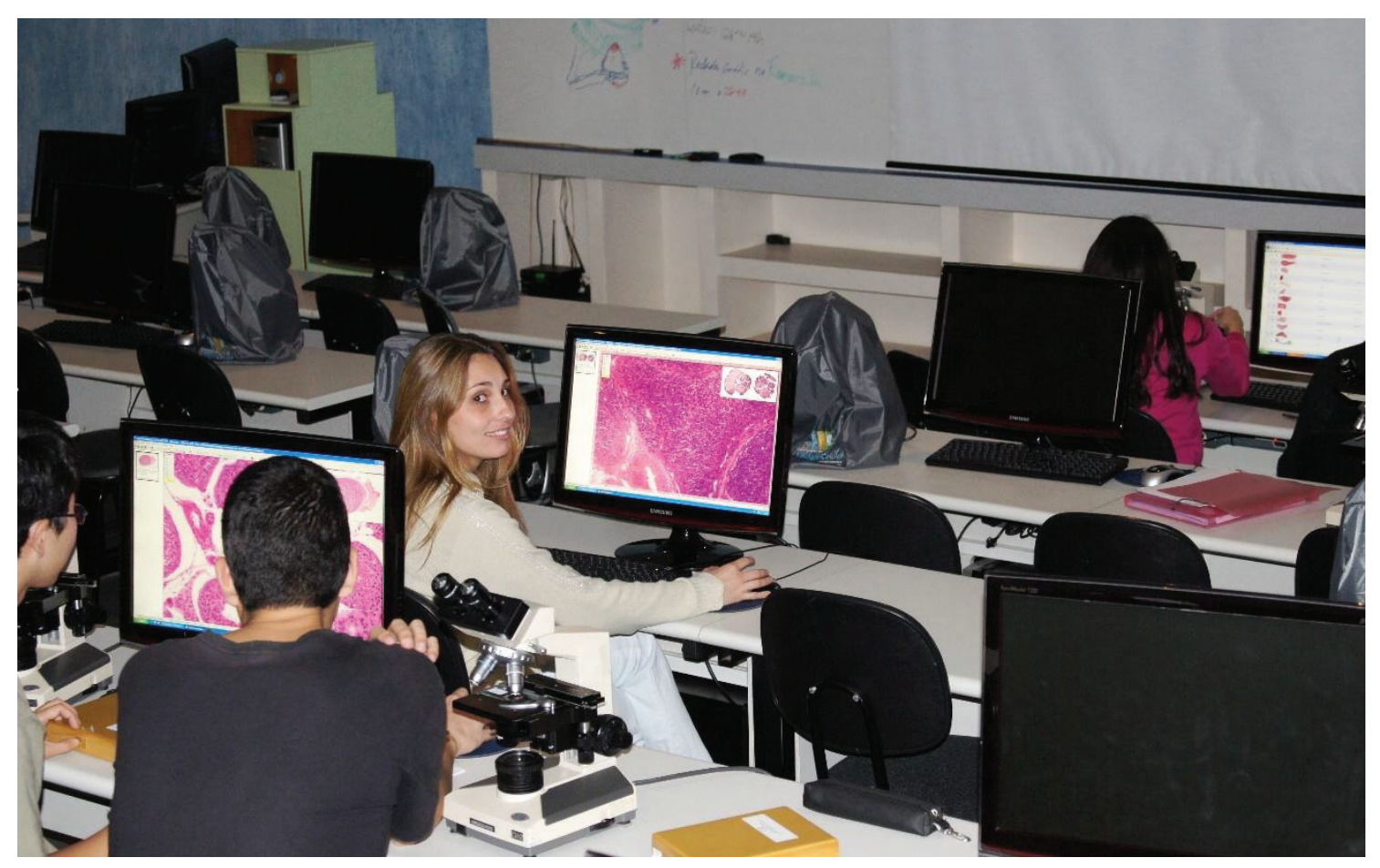

Figura 3 - Os estudantes se adaptam muito rapidamente ao recurso digital. Durante seus períodos de estudo podem simultaneamente visualizar diferentes lâminas ou criar conferências para estudar em grupos. Os microscópios e laminários de vidro continuam disponíveis e são utilizados no início das disciplinas. 
dência mundial (BLOODGOOD \& OGILVIE, 2006; CAMPBELL et al., 2010).

Para suprir essa demanda, produzimos um Laminário Virtual Online, com uma seleção de cem lâminas excepcionais que, associadas a um roteiro de estudos oferecido aos alunos, permitem que eles possam estudar em seus locais de conforto e fora dos horários de aula, acessando tal material a partir de computadores, celulares ou tablets.

A versão online do Laminário Virtual foi ao ar em 2014, depois de ser aprovada pelo Conselho do Departamento. Para disponibilização de tais conteúdos, utiliza-se uma solução baseada em software livre chamada OMERO ${ }^{1}$ (ALLAN et al., 2012), hospedada na Nuvem-USP, a qual oferece uma estrutura de rede que possibilita centenas de acessos simultâneos. Muito similar ao programa empregado em sala, o OMERO permite a visualização de lâminas em qualquer navegador ou por meio de um visualizador gratuito; possui ferramentas de análise de imagens, anotação, medição; aceita virtualmente todos os formatos de imagens existentes hoje em dia, até mesmo imagens médicas (DICOM) e reconstruções de microscopia confocal.

A disponibilização desse acervo não desestimulou o comparecimento às aulas ou os estudos presenciais. Em sentido contrário, acabou por estimular o estudo de Biologia Tecidual de forma rotineira no dia a dia do estudante.

Além disso, a existência dos novos recursos digitais em nossa instituição acabou por fomentar a criação de uma disciplina de pós-graduação sobre a prática de ensino em biologia tecidual mediante o uso de recursos digitais, o que vem permitindo capacitar novos monitores e futuros docentes.

\section{Considerações Finais}

O ensino de Biologia Tecidual é desafiador. Os estudantes precisam aprender a reconhecer elementos e projetar estruturas em três dimensões a partir de informações bidimensionais (MCMILLAN, 2001; MARSH et al., 2008). Assim como adquirir um novo vocabulário, o aprendizado de Histologia demanda estudo, treino e tempo. O uso de microscópios e lâminas convencionais restringe-se ao am- biente de ensino pela fragilidade, pelo elevado valor do equipamento e de sua manutenção periódica, bem como pela laboriosa confecção das lâminas. A adoção das ferramentas digitais aqui descritas aproximou o estudante do conteúdo da disciplina, pois o Laminário Virtual vale-se de mídias com as quais o aluno já está confortável. Além disso, possibilitou a diminuição significativa de custos, bem como tornou o modelo de ensino mais eficiente e próximo de um aprendizado ativo (BLOODGOOD, 2012).

Concluindo, estas iniciativas reforçam a imagem da instituição como entidade de ensino moderna, demonstrando um constante esforço na produção de conteúdo de boa qualidade e ferramentas didáticas adequadas. Esse zelo é, sem dúvida, percebido pelos alunos, como pôde ser aferido a partir de fóruns e formulários gerais de avaliação das disciplinas, que, em geral, revelam um retorno muito positivo, marcado por frequentes elogios e sugestões de mais atividades interativas.

\section{Agradecimentos}

Ao Departamento de Biologia Celular e do Desenvolvimento e ao Prof. Dr. Bayardo Baptista Torres.

\section{Nota}

1. Disponível em: 〈http://www.openmicroscopy.org >.

\section{Referências Bibliográficas}

ALLAN, Chris; BUREL, J.M.; MOORE, J.; BLACKBURN, G.; LINKERT, M.; LOYNTON, S.; MACDONALD, D. "OMERO: Flexible, Model-driven Data Management for Experimental Biology." Nature methods, vol. 9, n. 3, mar. 2012, pp. 245-253. Disponível em $>$ http://www.nature.com/nmeth/journal/v9/n3/pdf/ nmeth.1896.pd† $\gg$. Acessado em 15 jun. 2016.

BLOODGOOD, Robert Alan. "Active Learning: A Small Group Histology Laboratory Exercise in a Whole Class Setting Utilizing Virtual Slides and Peer Education". Anatomical Sciences Education, vol. 5, n. 6, nov.-dez. 2012, pp. 367-373.

BLOODGOOD, Robert Alan \& OGILVIE, R. W. "Trends in Histology Laboratory Teaching in United States Medical Schools". The Anatomical Record Part B: The New Anatomist, vol. 289, n. 5, set. 2006, pp. 169175. Disponível em <http://www.ncbi.nlm.nih.gov/pubmed/16955496>. Acessado em 15 jun. 2016. 
CAMPBELL, Gregor. "Research-Inspired Teaching and Teaching-Inspired Research". In: SALTER, Diane. J. (ed.). Cases on Quality Teaching Practices in Higher Education. Hershey, Pensilvânia: IGI Global, 2013.

CAMPBELL, Gregor; DEMETRIOU, L. A.; ARNETT, T. R. "Virtual Histology in the Classroom and Beyond. Medical Education, vol. 44, n. 11, nov. 2010, pp. 1124-1125. Disponível em <http://www.ncbi.nlm.nih. gov/pubmed/20946487>. Acessado em 20 jun. 2016.

JUNQUEIRA, Luiz Carlos \& CARNEIRO, J. Histologia Básica : Texto e Atlas. 12. Rio de Janeiro: Guanabara Koogan, 2013.

KRIPPENDORF, Beth B. \& LOUGH, J. "Complete and Rapid Switch from Light Microscopy to Virtual Microscopy for Teaching Medical Histology". The Anatomical Record
Part B: The New Anatomist, vol. 285, n. 1, jul. 2005, pp. 19-25.

MARSH, Karen R.; GIFFIN, B. F.; LOWRIE, D. J., JR. "Medical Student Retention of Embryonic Development: Impact of the Dimensions Added by Multimedia Tutorials". Anatomical Sciences Education, vol. 1, n. 6, nov.-dez. 2008, pp. 252-257. MCMILLAN, Paul J. "Exhibits Facilitate Histology Laboratory Instruction: Student Evaluation of Learning Resources". Anat Rec, vol. 265, n. 5, out. 2001, pp. 222-227.

MIONE, S.; VALCKE, M.; CORNELISSEN, M. Evaluation of virtual microscopy in medical histology teaching. Anatomical Sciences Education, vol. 6, n. 5, set.-out., 2013, pp. 307-315. Disponível em <http://www. ncbi.nlm.nih.gov/pubmed/23463716>. Acessado em 20 jun. 2016

Publicado em 05/07/2016. 